\title{
Study of the serum uric acid level as a prognostic indicator in hypertensive disorders of pregnancy
}

\author{
Smitha Krishnegowda*, G. Nita
}

Department of Obstetrics and Gynecology, KIMS, Bangalore, Karnataka, India

Received: 11 July 2021

Revised: 07 August 2021

Accepted: 09 August 2021

\section{*Correspondence:}

Dr. Smitha Krishnegowda,

E-mail: smithakeshava@gmail.com

Copyright: ( ) the author(s), publisher and licensee Medip Academy. This is an open-access article distributed under the terms of the Creative Commons Attribution Non-Commercial License, which permits unrestricted non-commercial use, distribution, and reproduction in any medium, provided the original work is properly cited.

\section{ABSTRACT}

Background: Abnormal uric acid levels in patients with preeclampsia and eclampsia affect both maternal and fetal outcome negatively. This study was done to know the alterations in these serum levels in comparison to normal pregnancy and also among various hypertensive disorders of pregnancies.

Methods: Maternal serum uric acid levels were compared among cases and controls in relation to disease severity, mode of delivery, maternal outcome.

Results: In group A (cases), 10 patients had raised uric acid levels, of which 5 were severe preeclampsia, 3 were eclampsia and 2 cases of chronic hypertension superimposed preeclampsia. $\mathrm{P}$ value is 0.001 (highly significant). Also serum uric acid is significantly elevated in hypertensive disorders of pregnancy compared with controls with a $\mathrm{P}$ value of 0.001 .

Conclusions: Significant correlation was observed between maternal serum uric acid, disease severity and maternal outcome. Our study concludes that uric acid can be considered as a sensitive prognostic indicator of severity in hypertensive disorders of pregnancy.

Keywords: Preeclampsia, Eclampsia, Uric acid

\section{INTRODUCTION}

Hypertensive disorders of pregnancy (HDP) is the most significant problem in obstetrics. The incidence of preeclampsia in hospital practice in India varies from 5\% to $15 \%$ and that of eclampsia about $1.5 \% .{ }^{1}$ The incidence of hypertensive disorders of pregnancy varies in the range of 1 to $35 \%$. $^{2}$ They represent one of the most common problems of pregnancy and lead to increased maternal and perinatal morbidity and mortality. Preeclampsia is a multisystem and multifactorial disease and causes cellular death. Abnormal uric acid levels in patients with preeclampsia and eclampsia affect both maternal and fetal outcome negatively. This study was done to know the alterations in these serum levels in comparison to normal pregnancy and also among various hypertensive disorders of pregnancies.

\section{METHODS}

In the department of obstetrics and gynecology in Kempegowda Institute of Medical Sciences, Bangalore. The duration of the study was 1 year i.e. from July 2020 to June 2021. The study is comprised of 80 pregnant women.

A total 40 patients with hypertensive disorders of pregnancy (group A) were included for the study and the results were compared with 40 normotensive patients (group B).

\section{Sampling method}

The type of sampling method used was purposive sampling. 


\section{Inclusion criteria}

A total 40 pregnant women diagnosed with hypertensive disorders of pregnancy admitted under obstetrics and gynecology department in Kempegowda Institute of Medical Sciences (group A). Results in group A were compared with 40 normotensive patients and they were selected according to the age of the patient and gestational age of the cases at the time of delivery for proper matching.

\section{Exclusion criteria}

In group $A$ and group $B$ patients with medical comorbidities like diabetes mellitus, liver disorder, renal disease, and cardiovascular disease were excluded from study.

\section{Methodology}

After taking informed written consent from all the patients' demographic features like age, gestation, parity etc. were recorder on structured data collection sheet. A detailed medical history of all participants was taken to ensure that they fulfill the inclusion criteria for study. This was followed by thorough physical examination of every case and control.

Blood pressure of all participants was measured using manual mercury sphygmomanometer twice for each patient at an interval of 15 to 20 minutes and then after 2 hours of rest, before labeling them as normotensive or with hypertensive disorder of pregnancy.

For all patients in group A and group B basic investigations were done along with uric acid. Estimation done using a fully automated biochemical analyser, COBAS c311.

\section{Ethical consideration}

All the patients and legal guardians were given an explanation of this study and about the investigations with their own merits and demerits. If he/she agreed, then the case had been selected for this study. This study did not involve any additional investigation or any significant risk to the patient. It did not cause economic burden to the patients. The study was approved by the institutional ethical committee board prior to commencement of data collection. Informed consent was taken from all patients and their guardians.

\section{Statistical data analysis}

The collected data were analysed with IBM statistical package for the social sciences (SPSS) statistics software 23.0 version. To describe about the data descriptive statistics frequency analysis, percentage analysis were used for categorical variables and the mean and standard deviation (SD) were used for continuous variables. To find the significant difference between the bivariate samples in independent groups the unpaired sample t-test was used. To find the significance in categorical data Chi-square test was used similarly if the expected cell frequency is less than 5 in $2 \times 2$ tables then the Fisher's exact was used. In all the above statistical tools the probability value 0.05 is considered as significant level.

\section{RESULTS}

Total 80 cases were studied of which, group A (cases) included 40 patients with hypertensive disorder of pregnancy, and group B (controls) included 40 normotensive pregnant women.

In my study group, majority of the patients belong to 21 to 25 years age group (age was matched with group A and group B for proper matching).

The youngest being 18 years and the oldest is 37 years.

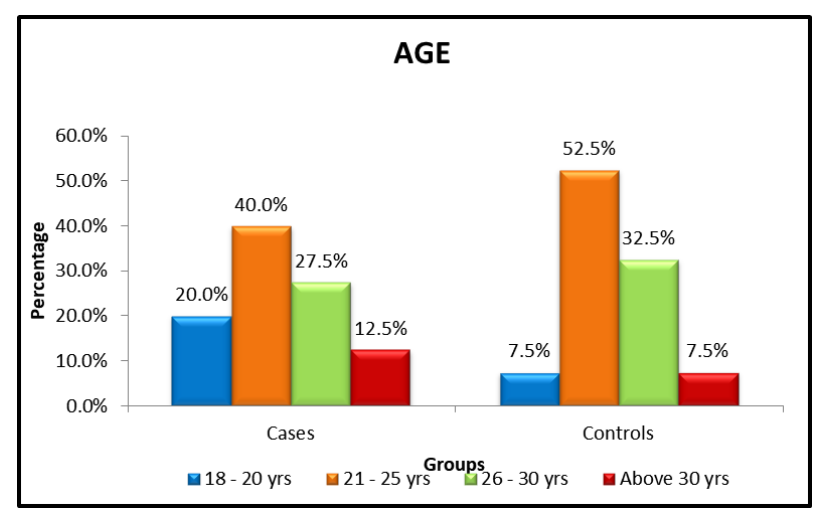

Figure 1: Age distribution.

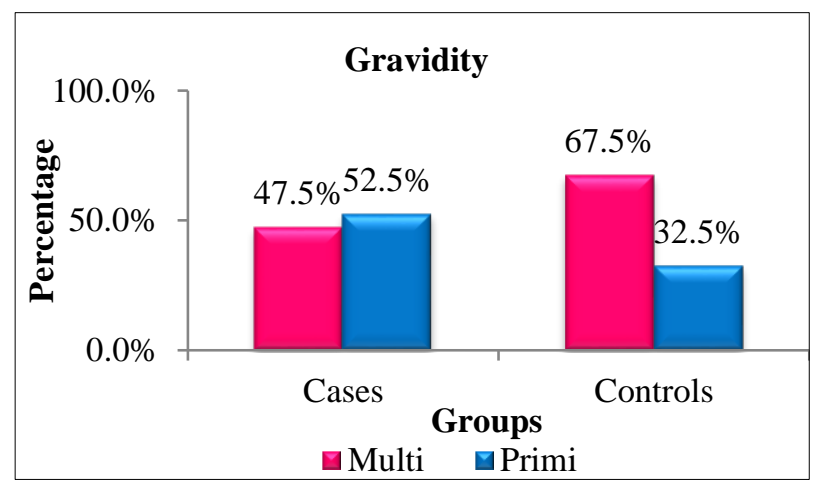

Figure 2: Gravidity distribution.

In group A (cases), majority were primigravidas constituting $52.5 \%$. In group B (controls), majority were multigravidas constituting $67.5 \%$.

Controls were selected according to the gestational age of cases for proper matching.

Majority of the patients were between the gestational age of 37 and $39+6$ weeks gestation in both group A and group B. 




Figure 3: Gestational age distribution.

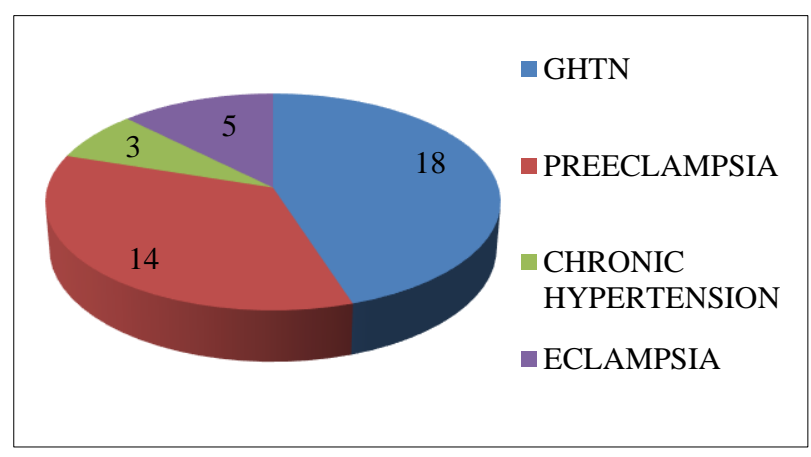

Figure 4: Distribution of types of hypertensive disorders of pregnancy among group a (cases).

Majority of the cases were diagnosed with gestational hypertension followed by preeclampsia and 5 were cases of eclampsia.

Among 14 preeclampsia cases, 5 were cases of severe preeclampsia.

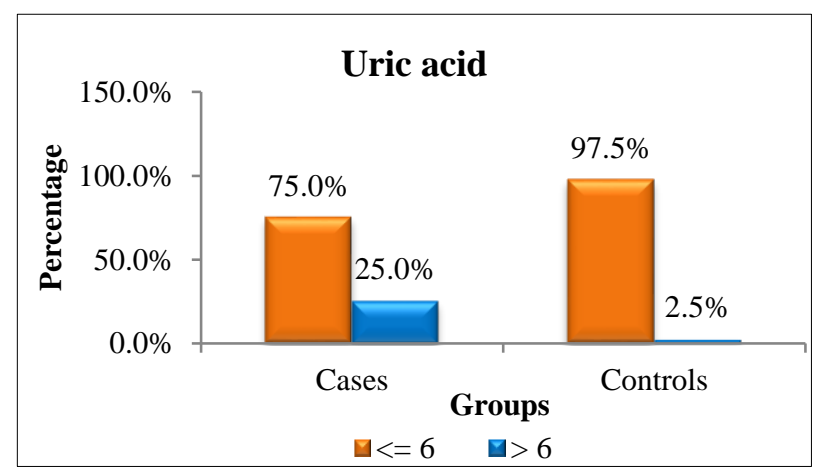

Figure 5: Comparison of uric acid levels among group $A$ and group $B$.

In group A (cases), 10 patients had raised uric acid levels, 5 were severe preeclampsia, 3 were eclampsia and 2 cases of chronic hypertension superimposed preeclampsia.

$\mathrm{P}$ value is 0.001 (highly significant).

Mean and standard deviation of group A (cases) are 5.18 and 1.64 respectively.
Mean and standard deviation of group B (controls) are 3.52 and 0.54 respectively.

\section{DISCUSSION}

There are numerous pathophysiological abnormalities in hypertensive disorders of pregnancy. These changes occur in large extent and are translated into a full clinical presentation of preeclampsia, during late pregnancy.

In this study, controls were selected after proper matching with the cases with respect to age of the patient and gestational age at the time of delivery.

In group A and group B maximum percentage of patients were in the age group of 21 to 25 years, with the mean age of 25 . According to Hazari et al mean age among cases was 23 and among controls were $25 .^{3}$

In group $\mathrm{A}$, primigravidas were more compared to multigravidas, constituting $52.5 \%$ and $47.5 \%$ respectively, which is consistent with various other studies. Primigravida is a proven risk factor for hypertensive disorders of pregnancy. According to Sajith et al highest incidence of hypertension was occurred in primigravida patients $(53.8 \%){ }^{4}$ Hansen reported a two to three fold increase in the incidence in primigravida and this was supported by Chesley. ${ }^{7}$ Sibai and his association recently reconfirmed the high risk of developing of pregnancy induced hypertension in primigravidas.

Most common hypertensive disorder of pregnancy found in this study was gestational hypertension followed by preeclampsia, which is consistent with federation of obstetric and gynaecological societies of India (FOGSI) which states approximately two third of hypertensive disorders of pregnancy are due to gestational hypertension and preeclampsia and one third are due to chronic hypertension.

Table 6: Comparison of uric acid levels with other studies.

\begin{tabular}{|lll|}
\hline $\begin{array}{l}\text { Authors and uric } \\
\text { acid levels }\end{array}$ & $\begin{array}{l}\text { Mean } \\
(\mathbf{m g} / \mathbf{d l})\end{array}$ & $\begin{array}{l}\text { Standard } \\
\text { deviation }\end{array}$ \\
\hline Naina et al, 2014. & & \\
\hline Cases & 6.8 & 2.72 \\
\hline Controls & 4.42 & 1.42 \\
\hline Meghal et al, 2018. & & \\
\hline Cases & 6.67 & 0.94 \\
\hline Controls & 4.2 & 1.11 \\
\hline Present study & & \\
\hline Group A (cases) & 5.18 & 1.64 \\
\hline Group B (controls) & 3.57 & 0.67 \\
\hline
\end{tabular}

Increase in uric acid can be detected earlier than the diagnosis of hypertension, proteinuria and preeclampsia. In the present study, the levels of uric acid were found to be significantly increased in group A (cases) when 
compared with group B (controls) $(\mathrm{p}=0.001)$. Uric acid is considered as biochemical marker of preeclampsia. In preeclampsia it is raised beyond the normal levels. This may be due to either decreased renal urate excretion or increased oxidative stress. The hyperuricemia of preeclampsia has been variably suggested to be associated with lactic acidosis, altered renal functions or oxidative stress. $^{8}$

\section{Limitations}

Sample size was small (as patients in group A (cases) were selected only with hypertensive disorders of pregnancy and patients with other comorbidities like diabetes, liver disorder, renal disease and cardiovascular disorders were excluded), we did not correlate the levels of parameter in different classification of hypertensive disorders of pregnancy and its complications.

\section{CONCLUSION}

The present study insists on the importance of serum levels uric acid on the management of hypertensive disorders of pregnancy and to significantly reduce the morbidity and mortality of the mother and fetus. On the basis of our results we conclude that uric acid is a sensitive indicator of severity in hypertensive disorders of pregnancy.

\section{ACKNOWLEDGMENTS}

Authors would like to thank head of the department, Dr. Jayanthy $\mathrm{T}$ and all the patients who submitted themselves gracefully and whole heartedly in this study without whose co-operation, this study would not have been possible.
Funding: No funding sources

Conflict of interest: None declared

Ethical approval: The study was approved by the Institutional Ethics Committee

\section{REFERENCES}

1. Nobis PN, Hajong A. Eclampsia in India through the decades. J Obstet Gynaecol India. 2016;66:172-6.

2. Chesley LC. Hypertensive Disorders in Pregnancy. New York: Appleton-Century- Crofts. 1978.

3. Hazari NR, Haltolkar VS, Munde SM. Study of hepatic enzymes in preeclampsia. Int J Curr Med Appl Sci. 2014(1).

4. Sajith M. Incidence of pregnancy induced hypertension and prescription pattern of antihypertensive drugs in pregnancy. IJPSR. 2014;6(4):164-6.

5. Kumar N. Maternal serum uric acid as a predictor of severity of hypertensive disorders of pregnancy. Curr Hypertens Rev. 2019;15(2):154-60.

6. Mehta M, Deokar P, Nagdeote A. A comparative study of serum uric acid, serum lactate dehydrogenase and serum calcium in hypertensive disorders of pregnancy and normal pregnancy. Int J Clin Biochem Res. 2019;6(1):90-4.

7. Aias F, Mancilla-Jimmenez R. hepatic fibrinogen deposits in pre-eclampsia. $\mathrm{N}$ Engl $\mathrm{J}$ Med. 1976;295:578.

8. Calbereath DF. Clinical chemistry a fundamental text book. W.B. Saunders. 1992;227-32.

Cite this article as: Smitha Krishnegowda, Nita G. Study of the serum uric acid level as a prognostic indicator in hypertensive disorders of pregnancy. Int $\mathbf{J}$ Reprod Contracept Obstet Gynecol 2021;10:3441-4. 